\title{
Violência conjugal física contra a mulher na vida: prevalência e impacto imediato na saúde, trabalho e família
}

\author{
Milma Pires de Melo Miranda, ${ }^{1}$ Cristiane Silvestre de Paula ${ }^{2,3}$ \\ e Isabel Altenfelder Bordin ${ }^{3}$
}

Como citar Miranda MPM, de Paula CS, Bordin IA. Violência conjugal física contra a mulher na vida: prevalência e impacto imediato na saúde, trabalho e família. Rev Panam Salud Publica. 2010;27(4):300-8.

RESUMO Objetivos. Estimar a prevalência de violência conjugal física contra a mulher ao longo da vida (VCFM) em uma comunidade urbana de baixa renda e avaliar o seu impacto imediato na saúde, trabalho e vida familiar.

Métodos. O presente estudo de corte transversal foi realizado em Embu, Estado de São Paulo, como componente do projeto multicêntrico internacional World Studies of Abuse in the Family Environment (WorldSAFE). Foi utilizada uma amostra probabilística de conglomerados derivados de setores censitários, incluindo todos os domicilios elegíveis identificados em cada um deles. Participaram 784 mulheres (16 a 49 anos) com pelo menos um filho menor de 18 anos e marido/companheiro residente (ao longo da vida). Foi avaliada a ocorrência de algum tipo de VCFM (tapa, chute, soco, espancamento, uso/ameaça de uso de arma, outras agressões físicas espontaneamente referidas), de VCFM grave (mesmos itens, exceto tapa e outras agressões referidas) e de impactos imediatos na saúde, trabalho e vida familiar das vitimas. Resultados. A prevalência de VCFM foi de $26,0 \%$ para algum tipo de violência e de 18,5\% para violência grave. Entre as vítimas de algum tipo de VFCM, 38,7\% julgaram necessitar cuidados médicos, 4,4\% foram hospitalizadas, 18,1\% ficaram incapacitadas para o trabalho (remunerado ou doméstico), 51,5\% separaram-se devido às agressões e 66,7\% tiveram filhos testemunhando a violência. Para a violência grave, essas taxas foram de 51,0, 5,5, 23,4, 59,3 e $75,9 \%$, respectivamente. A vergonha e o medo de represália por parte do companheiro dificultaram o acesso à assistência médica.

Conclusões. A VCFM é frequente na comunidade estudada e produz impactos imediatos na saúde, trabalho e vida familiar das vítimas. Esses impactos diminuem a capacidade da vítima de buscar socorro e dificultam a interrupção do ciclo da violência.

Palavras-chave Violência doméstica; violência contra a mulher; prevalência; impactos na saúde; impacto psicossocial; Brasil.

1 Universidade Federal de Alagoas, Faculdade de Medicina. Correspondência: Campus A. C. Simões, Faculdade de Medicina, Avenida Lourival Melo Mota s/n, Tabuleiro, CEP 57072-900, Maceió, AL, Brasil. E-mail: milminha@gmail.com

2 Universidade Presbiteriana Mackenzie, Programa de Pós-Graduação em Distúrbios do Desenvolvimento, São Paulo (SP), Brasil.

3 Universidade Federal de São Paulo (UNIFESP), Setor de Psiquiatria Social, São Paulo (SP), Brasil.
A violência contra a mulher é definida pela Organização das Nações Unidas (ONU) como qualquer ato de violência de gênero que resulte ou possa resultar em dano ou sofrimento físico, sexual ou psicológico para a mulher (1). Quando praticada por parceiro íntimo (marido, companheiro ou namorado, vivendo ou não sob o mesmo teto, atual ou pregresso), é designada por diversos termos, entre os quais "violência marital contra a mulher" e "violência conjugal contra a mulher". O parceiro íntimo é o mais importante perpetrador de violência física contra a mulher, mais frequente do que todos os outros perpetradores reunidos 
(2), mesmo em regiões em grave instabilidade política ou social (3). Estudos na população geral situam a prevalência da violência conjugal física contra a mulher durante a vida entre 10\% (Paraguai) e 69\% (Manágua, na Nicarágua) (4). Essa amplitude de prevalências reflete tanto características locais quanto diferenças entre as metodologias utilizadas nos diversos estudos. Um estudo multicêntrico da Organização Mundial da Saúde (OMS) (5), realizado tanto em comunidades urbanas quanto em regiões rurais de 10 países, porém utilizando metodologia semelhante, também encontrou uma grande variação na taxa de violência conjugal física contra a mulher durante a vida: de $13 \%$ na Cidade de Yokohama, Japão, a $61 \%$ na região rural do Peru. No Brasil, esse mesmo estudo encontrou prevalências de $27 \%$ na Cidade de São Paulo e de $34 \%$ na zona da mata pernambucana $(5,6)$.

A literatura aponta o alto consumo de álcool pelo parceiro íntimo e a exposição de crianças à violência doméstica (no papel de vítima ou de testemunha) como fatores associados à violência conjugal física contra a mulher, principalmente em comunidades pobres e em culturas que favorecem um menor empoderamento feminino (7-10). Nesse contexto, diversos fatores geram tensões que levam a agressões físicas, como a iniquidade econômica entre homens e mulheres dentro do lar, a dependência econômica feminina, impasses que levam a uma necessidade de afirmação masculina (como desemprego) e dificuldades de comunicação entre o casal no tocante às tomadas de decisões na família (11). Na Albânia, por exemplo, são agredidas as mulheres com nível educacional maior do que o do companheiro e aquelas com alto status ocupacional (12), enquanto na Nigéria as mulheres que têm idéias "avançadas" sobre o papel feminino são as que estão em maior risco de sofrer violência conjugal física (13).

O impacto socioeconômico da violência conjugal contra a mulher assume proporções importantes no mundo inteiro, e a complexidade do tema torna difícil mensurá-lo em todas as suas dimensões. Nos Estados Unidos, estimou-se em 5,8 bilhões de dólares o custo anual total da violência conjugal contra a mulher em 1995 (estupros, violência física e ameaças) (14). Desse montante, quase US\$ 4,1 bilhões foram gastos com cuidados à saúde física e mental, enquanto que cerca de US $\$ 1,7$ bilhões foram consumidos com perda de produtividade de vítimas não-fatais. Mais US\$ 1 bilhão foram perdidos com prejuízos à economia em função das vítimas fatais. Mesmo assim, esses dados ainda subestimam a importância do impacto, pois desconsideram outros prejuízos importantes, como aqueles relativos à saúde e à educação da população infantil oriunda de famílias onde ocorre a violência.

São numerosos os estudos enfocando o impacto da violência conjugal física na saúde da mulher vitimizada $(4,5,15-17)$. Esse impacto resulta de mecanismos diretos e indiretos através dos quais a violência leva ao adoecimento da mulher. O mecanismo direto envolve agressões físicas com ataques repetidos ou de alta intensidade que causam traumatismos (fraturas, hemorragias e deformidades físicas) ou problemas crônicos (dor crônica e osteoartrite). O mecanismo indireto está relacionado ao estresse psicológico crônico, que contribui para o desenvolvimento de hipertensão arterial, problemas gastrintestinais e geniturinários e transtornos mentais, e à adoção de comportamentos de risco que favorecem infecções e acidentes (15). Transtorno de estresse pós-traumático, depressão (com ou sem suicídio) e abuso e dependência de substâncias são transtornos psiquiátricos frequentes entre as mulheres vítimas de violência conjugal física $(15,17,18)$.

O impacto na saúde da mulher envolve ainda indicadores inespecíficos, tais como má saúde geral, má qualidade de vida e uso frequente dos serviços de saúde (10, $15,17,18)$. Como nem sempre a mulher relaciona os problemas vivenciados (tanto os de saúde quanto os ocupacionais ou familiares) à violência sofrida, já que podem surgir ou agravar-se cronologicamente distantes das agressões, é cabível a classificação dos impactos em imediatos e de médio ou longo prazo.

São impactos imediatos no trabalho o absenteísmo, os atrasos, a queda de produtividade $(14,19)$ e os distúrbios provocados diretamente pelo companheiro no local de trabalho $(2,19)$. Esses impactos geram grandes repercussões a longo prazo, na forma de instabilidade laboral, subemprego e empobrecimento da mulher vitimizada $(4,19,20)$. A dificuldade para manter o emprego costuma afetar mais fortemente as vítimas de classes sociais mais desfavorecidas do que as de maior status socioeconômico, principal- mente se houver impacto na saúde mental (20).

Quanto à família, são impactos imediatos a exposição dos filhos a um ambiente de violência dentro do lar e as separações. A separação do casal costuma adquirir feições próprias num contexto de violência, com maiores prejuízos econômicos e psicológicos e à saúde $(2,10)$. Esse agravamento é mediado principalmente pelo maior comprometimento que a violência produz na saúde da mulher e por aspectos legais envolvidos, como a custódia e a segurança dos filhos (2).

Filhos que testemunham violência entre os pais têm maior risco de apresentar problemas de adaptação social, delinquência e transtornos mentais, tanto na infância quanto posteriormente na vida adulta $(4,21,22)$, além de futuramente tornarem-se perpetradores ou vítimas de violência conjugal (transmissão intergeracional) (8-10). Todavia, ainda não está bem estabelecido quais parcelas dessas consequências podem ser atribuídas à exposição à violência conjugal ou a outros fatores, como os ambientais, que acompanham a violência, e os genéticos (22).

$\mathrm{Na}$ área da saúde são raros os estudos integrativos com enfoque nos impactos ocupacionais e familiares da violência conjugal física. Buscando contribuir com evidências, o projeto multicêntrico World Studies of Abuse in the Family Environment (WorldSAFE) conduziu estudos sobre a violência doméstica em 16 comunidades de cinco países em desenvolvimento (Brasil, Chile, Egito, Índia e Filipinas) através de colaboração multinacional e transdisciplinar (23). O presente estudo é fruto do componente brasileiro do WorldSAFE (Brazilian Studies of Abuse in the Family Environment/BrazilSAFE ou Estudo Brasileiro de Violência Doméstica contra a Criança e o Adolescente ${ }^{4}$ ) e tem os seguintes objetivos: estimar a prevalência de violência conjugal física contra a mulher ao longo da vida, perpetrada pelo marido ou companheiro atual ou pregresso, em uma comunidade urbana de baixa renda; avaliar o impacto imediato da violência conjugal física contra a mulher na saúde, no trabalho e na vida familiar; identificar fatores que impedem a mulher agredida de buscar assistência médica quando necessita;

\footnotetext{
4 Financiamento: Fundação de Amparo à Pesquisa do Estado de São Paulo/FAPESP (Processo no. 00/14555-4).
} 
identificar fatores que levam mulheres que se separam do companheiro agressor por causa das agressões físicas a retornarem à vida conjugal; e identificar os principais locais para onde se dirigem as mulheres vítimas de violência conjugal física durante os períodos de separação.

\section{PARTICIPANTES E MÉTODOS}

Este estudo de corte transversal foi conduzido em 2002 e 2003 no bairro Jardim Santo Eduardo, na Cidade de Embu, localizada na região metropolitana de São Paulo, capital do estado mais desenvolvido do Brasil. Em 2002, Embu era um município com 225629 habitantes, totalmente urbano, composto em sua maior parte por moradias de baixa renda, com altos índices de violência urbana (100,8 homicídios/100 000 habitantes/ano contra 38,9 homicídios/100 000 habitantes/ ano para o Estado de São Paulo) (24). Vale ressaltar que as evidências de violência conjugal ao longo da vida encontradas em 1999 no estudo piloto ( $n=86)$ (25) justificaram a realização do estudo completo (BrazilSAFE, $\mathrm{n}=813$ ), do qual a presente pesquisa é decorrente.

$\mathrm{O}$ presente estudo baseou-se em uma amostra probabilística por conglomerados, onde todos os domicílios elegíveis foram identificados. Em 24 conglomerados constituídos com base nas unidades censitárias para o bairro estudado e randomicamente selecionados pelo Instituto Brasileiro de Geografia e Estatística (IBGE), foram visitados 1545 domicílios. Foram identificados 996 domicílios elegíveis (residência de pelo menos uma mulher de 15 a 49 anos, mãe de pelo menos um menor de 18 anos também residente). Quando mais de uma mulher em um mesmo domicílio preenchia os critérios de elegibilidade, uma delas era escolhida por sorteio para fazer parte da amostra. Com base nesses critérios, o número de mulheres elegíveis foi de 987, por haverem sido excluídas da amostra nove mulheres que não mais residiam com um filho menor de 18 anos, que apresentavam problemas graves de saúde que impediam a comunicação ou por correrem risco de vida se participassem das entrevistas devido a ameaças de traficantes locais. Desse número ocorreram $174(17,6 \%)$ perdas, causadas principalmente por recusas em participar (84; $48,3 \%$ ) e mudança de domicílio (56; $32,2 \%$ ). Boa parte das recusas esteve associada ao medo das mães de fornecer informações sobre sua vida particular devido ao tráfico de drogas na região.

Assim, 813 mães completaram o questionário. Entretanto, a subamostra utilizada no presente trabalho refere-se às 784 mulheres que tinham, ou tinham tido, pelo menos um marido ou companheiro residente, ou seja, aquelas que estiveram expostas ao risco de sofrer violência conjugal física em algum momento de suas vidas, e para as quais havia dados completos sobre violência conjugal física na vida (sendo que das 813 mulheres apenas uma foi excluída pela ausência de dados completos sobre violência).

O estudo foi aprovado pelo Comitê de Ética em Pesquisa da Universidade Federal de São Paulo (UNIFESP). Todas as normas éticas foram cumpridas, inclusive a assinatura de termo de consentimento livre e esclarecido e o encaminhamento das vítimas de violência aos serviços especializados da região. Para garantir segurança e privacidade, todas as entrevistas foram realizadas individualmente na unidade básica de saúde local.

O desfecho clínico do estudo (violência conjugal física contra a mulher ao longo da vida por parte do marido ou companheiro, atual ou pregresso) e o impacto imediato das agressões físicas na saúde, família e trabalho da mulher foram investigados por meio de questionário padronizado, elaborado pelo comitê diretor do WorldSAFE. $^{5} \mathrm{O}$ instrumento foi aplicado face a face por entrevistadoras treinadas.

Considerou-se como violência conjugal física contra a mulher a ocorrência de pelo menos uma das seguintes agressões por parte do marido/companheiro: tapa, chute, soco, espancamento, uso/ameaça de uso de arma e outros. A ocorrência dessas agressões foi investigada com perguntas diretas e explícitas, por exemplo: "Deu soco em você?", exceto na categoria "outros", que agrupou todas as manifestações de violência física mencionadas espontaneamente pelas mulheres a partir das seguintes perguntas: "Machucou você fisicamente de alguma outra forma? Qual?". Definiu-se violência física grave como ocorrência de chute, soco, espancamento ou uso/ameaça de uso de arma.

\footnotetext{
A versão brasileira do Questionário WorldSAFE foi desenvolvida por Isabel A. Bordin e Cristiane S. Paula em 1999. O questionário pode ser obtido diretamente dessas pesquisadoras pelos e-mails iasbordin@gmail.com e csilvestrep@uol.com.br.
}

Os seguintes temas sobre o impacto imediato da violência conjugal física na vida da mulher foram abordados logo após as perguntas sobre os maus-tratos sofridos: a) julgamento da própria mulher quanto à necessidade de atendimento médico devido à violência sofrida; b) procura e obtenção do atendimento; c) impossibilidade de realizar tarefas domésticas e trabalho remunerado devido à violência sofrida; d) presença dos filhos no momento da agressão; e) separações do casal motivadas pela violência física e f) motivos que levaram as mulheres que se separaram a voltar à convivência com o marido/ companheiro agressor. A separação conjugal foi definida como a mudança de residência da mulher para uma casa diferente daquela onde vivia o marido/ companheiro, podendo essa separação ser temporária ou definitiva.

Os motivos que levaram à interrupção das separações foram agrupados em três categorias, aqui denominadas sentimentais, maternais e desamparo, podendo um mesmo motivo ter sido incluído em mais de uma categoria. Os motivos sentimentais incluíram ciúme, vingança, amor pelo marido/companheiro e esperança de recompor a família, entre outros. Os motivos maternais consideraram razões expressamente relacionadas ao bem estar dos filhos, tais como não querer abandoná-los, criança sentindo a falta do pai, acreditar na importância da figura paterna para a criança e nova gravidez. A categoria desamparo abarcou os motivos passíveis de interferência direta do Estado (por meio de ação policial, auxílio-moradia, colocação em emprego), tais como ameaças do companheiro à vida da mulher, dos parentes ou dos filhos, dependência econômica e falta de um abrigo para si e para os filhos.

A classe social foi determinada por meio do Questionário de Classificação Econômica Familiar da Associação Brasileira de Empresas de Pesquisa (ABEP), que avalia o poder de compra familiar (26). A análise estatística foi realizada com auxílio do programa Statistical Package for the Social Sciences (SPSS ${ }^{\circledR}$ versão 10.0), por meio de tabelas de frequência simples e tabelas cruzadas, utilizando-se os testes do qui-quadrado $\left(\chi^{2}\right)$ e razão de risco com intervalo de confiança de $95 \%$ (IC95\%), quando apropriado. Testes com $P<0,05$ foram considerados estatisticamente significativos. 


\section{RESULTADOS}

As mulheres da amostra $(\mathrm{n}=784)$ tinham idade entre 16 e 49 anos, com média de $33,4 \pm 7,6$ anos. Mais da metade $(413 ; 52,7 \%)$ não havia completado o ensino fundamental, com média de $7,1 \pm 3,3$ anos de escolaridade. Na época da entrevista, $401(51,1 \%)$ tinham trabalho remunerado. Outras características sociodemográficas da amostra encontram-se resumidas na tabela 1 .

A tabela 2 descreve a prevalência dos vários tipos de agressão. Das 204 mulheres que sofreram algum tipo de violência conjugal física, 145 (71\%) sofreram violência grave, $46(22,5 \%)$ foram agredidas a tapas sem outro tipo de agressão física e $13(6,4 \%)$ relataram exclusivamente agressões físicas classificadas em "outros". Essa categoria englobou agressões espontaneamente mencionadas pelas mulheres, como apertos, empurrões, mordidas, puxão de cabelo, queimaduras, tentativas de estrangulamento e arremesso de objetos contra o corpo da mulher.

As 176 mulheres que já haviam sido agredidas a tapas pelo marido/ companheiro apresentaram maior probabilidade de ter sofrido violência conjugal física grave (OR = 57,5; IC95\%: 34,0 a 97,$2 ; P<0,001)$ do que as 608 mulheres nunca agredidas a tapas. As mulheres agredidas a tapas também apresentaram probabilidade 24 vezes maior de ter sido ameaçadas com arma ou sofrido violência pelo uso de arma, em comparação com as mulheres nunca agredidas a tapas (IC95\%: 12 a 46; $P<0,001$ ). A tabela 3 mostra a frequência dos vários tipos de comportamento fisicamente agressivos do marido ao longo da vida (uma/duas vezes ou três ou mais vezes).

A tabela 4 descreve os impactos imediatos da violência conjugal sofrida pelas mulheres. Entre as 79 mulheres vítimas de algum tipo de violência que julgaram necessitar de cuidados médicos, 49 $(62,0 \%)$ não chegaram a receber assistência médica e uma $(1,3 \%)$ não soube informar. Entre as 74 mulheres vítimas de violência grave que julgaram necessitar de cuidados médicos, 46 (62,2\%) não chegaram a receber assistência médica e uma $(1,4 \%)$ não soube informar. Das 46 mulheres que foram agredidas exclusivamente a tapas, apenas uma $(2,2 \%)$ julgou necessitar de cuidados médicos, recebendo atendimento extra-hospitalar. Nenhuma dessas 46 mulheres referiu impacto imediato
TABELA 1. Características sociodemográficas das participantes de estudo sobre violência conjugal no Município de Embu (SP), Brasil, 2002 e 2003

\begin{tabular}{|c|c|c|}
\hline Característica & $\begin{array}{c}\text { No. } \\
(n=784)\end{array}$ & $\%$ \\
\hline \multicolumn{3}{|l|}{ Idade (anos) } \\
\hline 16 a 19 & 11 & 1,4 \\
\hline 20 a 29 & 254 & 32,4 \\
\hline 30 a 39 & 338 & 43,1 \\
\hline 40 a 49 & 181 & 23,1 \\
\hline \multicolumn{3}{|l|}{ Escolaridade (última série que completou) } \\
\hline Nunca estudou $/ 1^{a}$ série do ensino fundamental incompleta & 21 & 2,7 \\
\hline Entre $1^{\mathrm{a}}$ e $7^{\mathrm{a}}$ série & 392 & 50,0 \\
\hline $8^{\mathrm{a}}$ série & 113 & 14,4 \\
\hline $1^{\mathrm{a}}$ ou $2^{\mathrm{a}}$ série do ensino médio & 84 & 10,7 \\
\hline $3^{a}$ série do ensino médio & 143 & 18,2 \\
\hline Superior ao ensino médio & 31 & 4,0 \\
\hline \multicolumn{3}{|l|}{ Trabalho remunerado } \\
\hline Sim & 401 & 51,1 \\
\hline Não & 383 & 48,9 \\
\hline \multicolumn{3}{|l|}{ Classe Social } \\
\hline$A-B$ & 164 & 20,9 \\
\hline C & 401 & 51,1 \\
\hline D-E & 217 & 27,7 \\
\hline Sem informação & 2 & 0,3 \\
\hline \multicolumn{3}{|l|}{ Tipo de domicílio } \\
\hline Próprio ou pagando prestação & 489 & 62,4 \\
\hline Alugado & 162 & 20,7 \\
\hline Ocupação ou empréstimo & 131 & 16,7 \\
\hline Outros & 2 & 0,3 \\
\hline \multicolumn{3}{|l|}{ Número de maridos/companheiros residentes ao longo da vida } \\
\hline 1 & 679 & 86,6 \\
\hline 2 & 99 & 12,6 \\
\hline 3 & 6 & 0,8 \\
\hline
\end{tabular}

TABELA 2. Prevalência de violência conjugal física contra a mulher ao longo da vida, Município de Embu (SP), Brasil, 2002 e 2003

\begin{tabular}{|c|c|c|c|}
\hline \multirow[b]{2}{*}{ Tipo de agressão sofrida } & \multicolumn{3}{|c|}{ Prevalência ao longo da vida } \\
\hline & $\begin{array}{c}\text { No. } \\
(n=784)\end{array}$ & $\%$ & IC95\% \\
\hline Tapa com a mão aberta & 176 & 22,4 & 19,4 a 25,4 \\
\hline Soco & 89 & 11,4 & 9,1 a 13,7 \\
\hline Chute & 79 & 10,1 & 8,0 a 12,2 \\
\hline Espancamento & 60 & 7,7 & 5,8 a 9,6 \\
\hline Uso/ameaça de uso de arma & 69 & 8,8 & 6,8 a 10,8 \\
\hline Outros $^{a}$ & 51 & 6,5 & 4,7 a 8,3 \\
\hline Algum tipo de violência conjugal físicab & 204 & 26,0 & 22,9 a 29,1 \\
\hline Violência conjugal física grave ${ }^{c}$ & 145 & 18,5 & 15,7 a 21,3 \\
\hline Tapa sem outro tipo de agressão física & 46 & 5,9 & 4,2 a 7,6 \\
\hline
\end{tabular}

da agressão nas tarefas domésticas. As 49 mulheres vítimas de algum tipo de violência que julgaram necessitar de cuidados médicos, mas que não os receberam, alegaram os seguintes motivos: 17 $(34,7 \%)$ tiveram vergonha de expor o problema, $16(32,7 \%)$ disseram ter mudado de idéia e preferido não procurar atendimento, cinco $(10,2 \%)$ tiveram medo de represália por parte do marido, três $(12,5 \%)$ tiveram medo de comprometer o marido/ companheiro e no caso de uma $(6,1 \%)$ o marido/companheiro ou familiares não a deixaram ir, entre outros motivos menos frequentes. Nenhuma mulher deixou de buscar o serviço de saúde por ter recebido atendimento domiciliar, assim como nenhuma alegou problemas de acesso aos serviços de saúde por dificuldades com transporte ou distância. 
TABELA 3. Frequência de comportamentos agressivos do marido ao longo da vida no estudo sobre violência conjugal no Município de Embu (SP), Brasil, 2002 e 2003a

\begin{tabular}{lrrrr}
\hline \multirow{2}{*}{ Tipo de agressão sofridab } & \multicolumn{2}{c}{ 1 ou 2 vezes } & \multicolumn{2}{c}{3 ou mais vezes } \\
\cline { 2 - 3 } \cline { 5 - 5 } & No. & $\%$ & No. & \% \\
\hline Tapa com a mão aberta & 102 & 13,0 & 74 & 9,4 \\
Soco & 49 & 6,3 & 40 & 5,1 \\
Chute & 44 & 5,6 & 35 & 4,5 \\
Espancamento & 24 & 3,1 & 36 & 14 \\
Uso/ameaça de uso de arma $_{\text {Outros }^{c}}$ & 55 & 7,0 & 10 & 1,8 \\
& 41 & 5,2 & & 1,3 \\
\hline
\end{tabular}

a $n=784$.

b Possibilidade de respostas múltiplas.

c Relatos espontâneos envolvendo: tentativas de estrangulamento, apertos, mordidas, empurrões, puxão de cabelo, queimaduras e arremesso de objetos contra o corpo da mulher.

O impacto imediato da violência conjugal física sobre a capacidade de realizar atividades remuneradas foi avaliado apenas para as mulheres que trabalhavam na época das agressões. Entre as 162 mulheres que exerciam uma atividade remunerada e foram vitimizadas por algum tipo de violência conjugal física, 111 sofreram violência física grave. A taxa de incapacitação para o trabalho remunerado dessas 111 mulheres foi de $16,2 \%$. Nenhuma das 42 mulheres que exerciam atividades remuneradas e que foram agredidas exclusivamente a tapas referiu impacto imediato no trabalho.

Quanto ao impacto imediato da violência conjugal física sobre a vida familiar, a taxa de separação definitiva foi maior entre as mulheres que se separaram uma única vez do que entre as mul- heres que se separaram duas ou mais vezes. Das 105 vítimas de algum tipo de violência conjugal física que se separaram, $60(57,1 \%)$ o fizeram uma única vez e $45(42,9 \%)$ se separaram duas vezes ou mais. Entre as 60 mulheres que sofreram algum tipo de violência conjugal física e se separaram uma única vez, a separação foi definitiva para $36(60,0 \%)$. Entre as 45 mulheres vítimas de algum tipo de violência com duas ou mais separações, apenas duas $(4,4 \%)$ se separaram definitivamente. Além disso, entre as 86 vítimas de violência grave que se separaram, $46(53,5 \%)$ se separaram uma única vez e $40(46,5 \%)$ se separaram duas vezes ou mais. Entre as 46 mulheres que sofreram violência grave e se separaram uma única vez, a separação foi definitiva para $29(63,0 \%)$, enquanto que entre as 40 mulheres vítimas de violência grave com duas ou mais separações, duas $(5,0 \%)$ se separaram definitivamente. Finalmente, $12(26,1 \%)$ das 46 mulheres agredidas a tapas na ausência de outros tipos de agressão física se separaram. Dessas 12 mulheres, $10(83,3 \%)$ se separam uma única vez e duas $(16,7 \%)$ se separaram duas ou mais vezes. Entre as 10 que se separaram uma só vez, a separação foi definitiva para cinco (50\%), enquanto que as duas mulheres (100\%) que se separaram duas ou mais vezes voltaram a residir com o marido/companheiro agressor.

Como motivos para o retorno à vida conjugal com seus agressores, das 67 mulheres que se separaram do marido/ companheiro por ter sofrido algum tipo de violência, mas que não levaram adiante a separação, 38 alegaram razões sentimentais $(56,7 \%), 24$ alegaram razões maternais $(35,8 \%)$ e 31 alegaram desamparo $(46,3 \%)$. Das 55 mulheres que se separaram do marido/companheiro por ter sofrido violência grave, mas que não levaram adiante a separação, 31 também referiram razões sentimentais $(56,4 \%), 20$ alegaram razões maternais $(36,4 \%)$ e 29 alegaram desamparo $(52,7 \%)$.

Na maioria das separações, tanto naquelas causadas por algum tipo de violência conjugal física quanto naquelas decorrentes de violência conjugal grave, foram as mulheres que deixaram a casa. A tabela 5 mostra os locais procura-

TABELA 4. Impacto imediato da violência conjugal física ao longo da vida na saúde, trabalho e vida familiar da mulher no estudo sobre violência conjugal no Município de Embu (SP), Brasil, 2002 e 2003

\begin{tabular}{|c|c|c|c|c|c|c|c|c|c|}
\hline \multirow[b]{3}{*}{ Impacto imediato } & \multicolumn{6}{|c|}{ Vítimas de violência conjugal física na vida } & \multirow{2}{*}{\multicolumn{3}{|c|}{$\begin{array}{l}\text { Número de vítimas em } \\
\text { relação à amostra } \\
\text { total }(n=784)\end{array}$}} \\
\hline & \multicolumn{3}{|c|}{$\begin{array}{l}\text { Algum tipo } \\
(n=204)\end{array}$} & \multicolumn{3}{|c|}{$\begin{array}{c}\text { Grave } \\
(n=145)\end{array}$} & & & \\
\hline & No. & $\%$ & IC 95\% & No. & $\%$ & IC 95\% & No. & $\%$ & IC 95\% \\
\hline \multicolumn{10}{|l|}{ Na saúde } \\
\hline Julgou necessitar de cuidados médicos & 79 & 38,7 & 31,9 a 45,5 & 74 & 51,0 & 46,9 a 55,2 & 79 & 10,1 & 8,0 a 12,3 \\
\hline Chegou a receber cuidados médicos & 29 & 14,2 & 9,3 a 19,1 & 27 & 18,6 & 12,1 a 25,1 & 29 & 3,7 & 2,4 a 5,1 \\
\hline Já foi hospitalizada por causa das agressões & 9 & 4,4 & 1,5 a 7,3 & 8 & 5,5 & 1,7 a 9,3 & 9 & 1,2 & 0,4 a 2,0 \\
\hline Por 1 semana ou mais & 16 & 7,8 & 4,0 a 11,6 & 14 & 9,7 & 4,8 a 14,5 & 16 & 2,0 & 1,0 a 3,0 \\
\hline Incapacitada para trabalho remunerado & 18 & 8,8 & 4,8 a 12,8 & 18 & 12,4 & 7,0 a 17,9 & 18 & 2,3 & 1,2 a 3,4 \\
\hline Por 1 semana ou mais & 7 & 3,4 & 0,9 a 5,9 & 7 & 4,8 & 1,2 a 8,4 & 7 & 0,9 & 0,2 a 1,6 \\
\hline Incapacitada para trabalho remunerado ou & & & & & & & & & \\
\hline doméstico ${ }^{b}$ & 37 & 18,1 & 12,7 a 23,5 & 34 & 23,4 & 16,4 a 29,1 & 37 & 4,7 & 3,2 a 6,2 \\
\hline \multicolumn{10}{|l|}{ Na vida familiar } \\
\hline Separação conjugalc & 105 & 51,5 & 44,5 a 58,5 & 86 & 59,3 & 51,2 a 67,4 & 105 & 13,4 & 11,0 a 15,8 \\
\hline
\end{tabular}

a Engloba as vítimas de violência grave.

${ }^{b}$ Inclui as mulheres com e sem trabalho remunerado na época das agressões.

${ }^{c}$ Inclui separações temporárias e definitivas. 
TABELA 5. Locais procurados pelas vítimas de violência conjugal física que se separaram, estudo sobre violência conjugal no Município de Embu (SP), Brasil, 2002 e 2003

\begin{tabular}{|c|c|c|c|c|}
\hline \multirow[b]{3}{*}{ Local $^{\mathrm{a}}$} & \multicolumn{4}{|c|}{ Violência conjugal física } \\
\hline & \multicolumn{2}{|c|}{$\begin{array}{l}\text { Algum tipo } \\
(n=105)\end{array}$} & \multicolumn{2}{|c|}{$\begin{array}{l}\text { Grave } \\
(n=86)\end{array}$} \\
\hline & No. & $\%$ & No. & $\%$ \\
\hline Casa de parentes da mulher & 67 & 63,8 & 54 & 62,8 \\
\hline Ficou em casa e marido/companheiro saiu & 16 & 15,2 & 14 & 16,3 \\
\hline Foi para outra casa própria ou alugada & 16 & 15,2 & 12 & 14,0 \\
\hline Casa de amigos da mulher & 7 & 6,7 & 7 & 8,1 \\
\hline Casa de parentes do marido/companheiro & 2 & 1,9 & 2 & 2,3 \\
\hline Hotel/motel/pensão & 1 & 1,0 & 1 & 1,2 \\
\hline Foi morar com outro homem & 1 & 1,0 & 1 & 1,2 \\
\hline Abrigos & 0 & 0,0 & 0 & 0,0 \\
\hline Igreja/templo & 0 & 0,0 & 0 & 0,0 \\
\hline Centro comunitário & 0 & 0,0 & 0 & 0,0 \\
\hline
\end{tabular}

${ }^{a}$ Foram aceitas respostas múltiplas.

dos por essas mulheres para residir ao saírem de casa. Nenhuma mulher vitimizada que se separou em função da violência referiu o acolhimento por abrigos, igrejas/templos ou centros comunitários.

\section{DISCUSSÃO}

Este trabalho encontra-se entre os raros estudos de prevalência de violência conjugal física contra a mulher em população geral no Brasil e tem o mérito adicional de ser o primeiro estudo epidemiológico brasileiro a estudar o impacto dessa violência enfocando três diferentes áreas da vida das mulheres vitimizadas. No entanto, algumas limitações precisam ser reconhecidas. O conceito de violência conjugal física utilizado pode ter subestimado a prevalência dessa situação, uma vez que outras manifestações de violência (como empurrar, beliscar, puxar o cabelo, torcer o braço) não foram ativamente pesquisadas, ficando sua identificação dependente de um relato espontâneo por parte das mulheres, reunidos na categoria "outros". Como esses atos nem sempre são considerados pelas mulheres como violência, muitas podem ter deixado de mencioná-los, minimizando a ocorrência de violência conjugal.

Quanto à possibilidade de perda amostral seletiva, as principais causas de perda foram recusas e mudança de domicílio e, de fato, não é possível saber se as 85 mulheres que se recusaram a participar do estudo eram ou não vítimas de violência conjugal física. Se essas tivessem participado do estudo (para uma amostra total de 897 mulheres) e tives- sem sofrido violência conjugal física na vida (fazendo aumentar o número de mulheres vitimizadas de 204 a 288), a taxa de prevalência de violência conjugal seria de $32,1 \%$, valor próximo do limite superior do IC95\%, de 22,9 a 29,1, encontrado na presente pesquisa. Outro ponto a ser considerado é o fato de o foco deste estudo ter sido uma amostra populacional de mães, com exclusão das mulheres sem filhos, que também são passíveis de sofrer violência conjugal física. Portanto, o recorte do estudo poderia levar a resultados subestimados nas taxas de prevalência encontradas. No entanto, sendo a nuliparidade uma condição infrequente na faixa populacional estudada (27), é razoável supor que a prevalência encontrada não seria alterada de forma significativa. Finalmente, o desenho transversal do estudo foi adequado para estimar a prevalência de violência conjugal física contra a mulher ao longo da vida, mas levou a limitações nas medidas de impacto, por viés de recordação.

A definição de violência conjugal física contra a mulher utilizada nesta pesquisa favorece a comparação com importantes estudos de prevalência realizados em outros países, sendo similar à definição utilizada pelo mais recente estudo multicêntrico da OMS (5) e equivalente à do estudo WorldSAFE (28) realizado no Chile, Egito, Índia e Filipinas. Embora as publicações do WorldSAFE tenham excluído os itens "uso/ameaça de uso de arma" e "outros" da definição de violência conjugal física, pois nem todos os países participantes os investigaram, este fato não comprometeu a comparabilidade dos dados do presente trabalho, por serem essas agressões frequente- mente concomitantes com outros tipos de agressão física investigados. Além disso, a coleta de dados, realizada na privacidade da unidade básica de saúde local por entrevistadores exclusivamente do sexo feminino favoreceu a sinceridade no relato de violência. Contudo, pela natureza íntima do assunto pesquisado, não se pode afirmar que os resultados não tenham sido subestimados.

$\mathrm{Na}$ fase piloto do BrazilSAFE (25), as taxas de violência conjugal física na vida [algum tipo: 33,7\% (IC95\%: 32,7 a 34,7); grave: $22,1 \%$ (IC95\%: 13,3 a 30,9)] foram mais elevadas que as observadas no presente estudo. Como as duas amostras populacionais eram provenientes de bairros vizinhos e apresentavam composição socioeconômica muito semelhante, é mais provável que as variações encontradas se devam à menor precisão das taxas de prevalência do estudo piloto, decorrentes do pequeno tamanho da amostra $(n=86)$ do que a reais diferenças entre as comunidades estudadas.

Em comparação às prevalências encontradas em populações urbanas dos demais países participantes do WorldSAFE (28), a taxa de algum tipo de violência conjugal física na vida encontrada no presente trabalho (26\%; IC95\%: $22,9$ a 29,1$)$ mostrou-se similar à encontrada no Chile $(24,9 \%)$, próxima das taxas encontradas nas Filipinas $(21,2 \%)$ e em Vellore, na Índia $(31,0 \%)$, inferior às de duas outras comunidades da Índia (Lucknow, 34,6\%, e Trivandrum, 43,1\%) e superior à encontrada no Egito $(11,1 \%)$. A prevalência de violência conjugal física contra a mulher no presente estudo situa-se em nível inferior ao da maioria das populações urbanas dos países em desenvolvimento estudados pela OMS (Tanzânia, 32,9\%; Bangladesh, 39,7\%; Peru, 48,6\%), na mesma faixa de Sérvia e Montenegro (22,8\%) e Tailândia $(22,9 \%)$ e bem superior aos $12,9 \%$ encontrados no desenvolvido Japão (5). A prevalência encontrada no Município de Embu é compatível com a taxa identificada para a Cidade de São Paulo (27,2\%; IC95\%: 23,9 a 30,6) no mesmo estudo da OMS (5), e previsivelmente inferior à encontrada na zona da mata pernambucana (33,8\%; IC95\%: 30,8 a 36,7) (6). As regiões rurais costumam apresentar números mais elevados, provavelmente em decorrência de características mais patriarcais nas relações de gênero, muitas vezes entrelaçadas a menor renda e nível educacional baixo $(11,29)$. Outro trabalho 
sobre violência conjugal no Brasil (30), realizado em 15 capitais, não pode ser comparado com o presente estudo, já que não contemplou a violência conjugal física contra a mulher ao longo da vida.

Os resultados do presente estudo sobre impacto na saúde oferecem apenas uma estimativa do impacto imediato, já que problemas cronologicamente distantes das agressões físicas sofridas foram desconsiderados. A parcela $(38,7 \%)$ de mulheres vítimas de algum tipo de violência conjugal física que julgaram necessitar de cuidados médicos devido às agressões foi bem superior aos $10 \%$ identificados em uma população canadense (31), o que está de acordo com a literatura, que atribui a intensidade do impacto da violência conjugal sobre a saúde da mulher à interação entre fatores relacionados ao menor nível socioeconômico (como estado nutricional deficitário, traumatismos prévios e história de abuso na infância) e às características da agressão sofrida (natureza, intensidade e duração) (32).

A taxa de mulheres vítimas de algum tipo de violência conjugal física que chegaram a receber cuidados médicos entre as que julgaram necessitá-los $(36,7 \%)$ é menor que a encontrada na Índia $(50 \%)$ (33). No presente estudo, os principais motivos alegados para não receber os cuidados médicos não incluíram a falta de acesso aos serviços de saúde, mas concentraram-se principalmente em razões pessoais, como vergonha de expor seu problema ou medo de receber represália do marido/companheiro. $\mathrm{Na}$ Índia, a falta de acesso aos serviços (30\%) ainda é uma importante limitação para a busca de cuidados médicos, o que provavelmente também ocorre em regiões menos desenvolvidas do Brasil.

Quanto ao impacto ocupacional, um estudo de revisão encontrou uma variação de 23 a $54 \%$ para a taxa de mulheres vitimizadas que faltaram ao emprego devido à violência conjugal física sofrida (19). Essa faixa é bem superior aos 11,1\% encontrados no presente estudo entre as mulheres vítimas de algum tipo de violência conjugal física com trabalho remunerado na época em que sofreram agressões, e também superior aos 16,2\% observados entre as vítimas de violência grave. Essa diferença pode, em parte, ser explicada pelo caráter menos restritivo da medida utilizada no estudo de revisão, que incluiu não somente as faltas ao trabalho provocadas por ferimentos, mas também as faltas para buscar ajuda policial ou para esconder-se do marido.

Quanto às tarefas domésticas, 14,2\% das vítimas de algum tipo de violência conjugal e 17,9\% das vítimas de violência grave referiram incapacitação. De fato, a perda de dias de trabalho e a improdutividade nas tarefas do lar são efeitos frequentemente observados da violência conjugal física, inclusive em países mais desenvolvidos. Nos Estados Unidos, as vítimas de violência conjugal física grave perdem anualmente cerca de 8 milhões de dias de trabalho remunerado, o equivalente a mais de 32000 empregos de tempo integral, e quase 5,6 milhões de dias de produtividade referentes às tarefas domésticas (34).

No presente estudo, 51,5\% das mulheres que sofreram algum tipo de violência conjugal física e 59,3\% das mulheres que sofreram violência conjugal física grave separaram-se de seus maridos. Essas taxas estão inseridas na variação de 38 a $63 \%$ encontrada em estudo de revisão sobre o tema (2). Vale destacar que, tanto no presente trabalho quanto na literatura (10), as razões sentimentais são as mais frequentes para justificar a manutenção da relação com o agressor, mais relevantes do que os problemas materiais ou com os filhos e, portanto, devem ser levadas em consideração no desenvolvimento de modelos de intervenções para prevenção de violência conjugal contra mulheres.

$\mathrm{Na}$ amostra estudada, a maioria das mulheres vitimizadas, tanto por algum tipo de violência conjugal física quanto por violência grave $(51,5$ e $59,3 \%$, respectivamente), separaram-se de seus companheiros por causa das agressões. Porém, quase dois terços $(63,8$ e $63,9 \%$, respectivamente) das mulheres voltaram a conviver com o companheiro. Dados do presente estudo assemelham-se aos encontrados no Canadá (31) e na Nicarágua (35), indicando que a separação de um marido agressivo é um processo que envolve várias saídas e retornos ao relacionamento. Em um levantamento populacional conduzido no Canadá, $43 \%$ das mulheres vítimas de violência conjugal deixaram seus companheiros em decorrência de agressões, embora a maior parte delas, cedo ou tarde, tenha voltado para casa. Na Nicarágua, $41 \%$ das mulheres agredidas separaram-se temporariamente de seus maridos, enquanto que $38 \%$ separaram-se permanentemente. Segundo a OMS (4), o medo é uma das razões para essas idas e vindas. $\mathrm{Na}$ Índia, a preocupação com a honra da família foi um dos principais motivos levantados por pesquisadores do WorldSAFE para explicar a baixa taxa de separações em decorrência da violência conjugal $(7 \%)$ e a elevada proporção de separações temporárias $(84 \%)$ (33). Outras razões referidas pelas mulheres vitimizadas na Índia para voltar a conviver com o marido incluíram o pedido do marido para que voltasse e ter sido convencida a voltar pela própria família (36).

Outro importante impacto da violência conjugal física na família é o que se dá sobre a saúde mental dos filhos que a presenciam. Crianças que testemunham violência entre os pais têm maior probabilidade de apresentar uma série de problemas emocionais e comportamentais, incluindo ansiedade e depressão, baixa autoestima, desobediência, pesadelos e queixas somáticas, além de baixo desempenho escolar $(4,21,22)$. $\mathrm{Na}$ amostra estudada, $17,3 \%$ de todas as mulheres referiram o testemunho da violência conjugal pelas crianças. Essa taxa chegou a $66,7 \%$ nos lares onde ocorria algum tipo de violência conjugal física contra a mulher e a $75,9 \%$ nos lares onde ocorria violência conjugal grave. Os dados do presente estudo aproximam-se dos encontrados em Dunedin (21), na Nova Zelândia, onde $20 \%$ de 962 adultos de 26 anos na população geral relataram ter testemunhado durante a infância agressão conjugal física ou ameaças contra a mãe, enquanto $66 \%$ das mães vítimas de violência conjugal tinham conhecimento do testemunho dos filhos às agressões. Também é importante salientar que as crianças que crescem em lares onde há violência conjugal tendem a repetir os padrões de comportamento dos pais. As meninas, ao se tornarem adultas, podem se envolver em relacionamentos violentos, enquanto os meninos podem se tornar parceiros agressores, perpetuando o ciclo da violência em relações futuras $(9,10,22)$. Portanto, a alta frequência com que as crianças testemunham violência contra suas mães e a gravidade das consequências para essas crianças e seus descendentes $(4,8-11,21$, 22) aumentam a relevância do problema e a importância de sua abordagem em caráter interdisciplinar nos diversos níveis de atenção à saúde.

A multiplicidade de impactos da violência conjugal física repercute na vida da mulher mais fortemente do que 
simplesmente a soma desses impactos (2) e não resulta necessariamente em ações que diminuam ou eliminem as agressões por parte do companheiro. Os impactos na saúde, no trabalho e na vida familiar tendem a restringir a autonomia da mulher vitimizada e a afetar sua capacidade para uma busca efetiva de socorro. As evidências derivadas do presente estudo indicam a necessidade de uma maior disponibilidade e visibilidade de órgãos de assistência às vítimas de violência doméstica. É recomendável que essa assistência tenha caráter inter- disciplinar e que possa enfocar aspectos ocupacionais, legais e de segurança, além do cuidado em saúde para todos os familiares envolvidos, sem negligenciar os aspectos sentimentais da relação conjugal.

A relevância do tema, sua complexidade e a escassez de estudos disponíveis no Brasil conduzem à necessidade de novas pesquisas. Faltam avaliações da efetividade de iniciativas governamentais já implementadas de combate à violência doméstica, como a lei 11340 (conhecida como lei Maria da Penha), aprovada em 2006, que intensifica as penas para perpetradores de violência conjugal. Faltam também estudos que identifiquem as taxas de violência conjugal física seguida de morte, assim como pesquisas que estimem os custos econômicos da violência conjugal contra a mulher no Brasil. Finalmente, são necessários estudos longitudinais para esclarecer os mecanismos envolvidos no surgimento e na perpetuação da violência conjugal, fornecendo dados que possam embasar estratégias de intervenção e de prevenção mais efetivas.

\section{REFERÊNCIAS}

1. Watts C, Zimmerman C. Violence against women: global scope and magnitude. Lancet. 2002;359(9313):1232-7.

2. Walker R, Logan TK, Jordan CE, Campbell JC. An integrative review of separation in the context of victimization: consequences and implications for women. Trauma Violence Abuse. 2004;5(2):143-93.

3. Hynes M, Robertson K, Ward J, Crouse C. A determination of the prevalence of gender-based violence among conflict-affected populations in East Timor. Disasters. 2004;28(3):294-321.

4. Heise L, Garcia-Moreno C. Violence by intimate partners. Em: Krug EG, Dahlberg LL, Mercy JA, Zwi AB, Lozano R, eds. World report on violence and health. Genebra: WHO; 2002. Pp. 87-121.

5. Garcia-Moreno C, Jansen HA, Ellsberg M, Heise L, Watts C, WHO Multi-country Study on Women's Health and Domestic Violence against Women Study Team. Prevalence of intimate partner violence: findings from the WHO multi-country study on women's health and domestic violence. Lancet. 2006; 368(9543):1260-9.

6. Schraiber LB, D'Oliveira AFPL, França-Junior I, Diniz S, Portella AP, Ludermir AB, et al. Prevalência da violência contra a mulher por parceiro íntimo em regiões do Brasil. Rev Saude Publica. 2007;41(5):797-807.

7. Pan American Health Organization. Unhappy hours: alcohol and partner aggression in the Americas. Washington: PAHO; 2008.

8. Jewkes R. Intimate partner violence: causes and prevention. Lancet. 2002;359(9315):1423-9.

9. Koenig MA, Stephenson R, Ahmed S, Jejeebhoy SJ, Campbell J. Individual and contextual determinants of domestic violence in North India. Am J Public Health. 2006;96(1):132-8.

10. Langhinrichsen-Rohling J. Top 10 greatest "hits": important findings and future directions for intimate partner violence research. J Interpers Violence. 2005;20:108-18.

11. Gage AJ. Women's experience of intimate partner violence in Haiti. Soc Sci Med. 2005; 61(2):343-64.
12. Burazeri G, Roshi E, Jewkes R, Jordan S, Bjegovic V, Laaser U. Factors associated with spousal physical violence in Albania: cross sectional study. BMJ. 2005;331(7510):197-201.

13. Okemgbo CN, Omideyi AK, Odimegwu CO. Prevalence, patterns and correlates of domestic violence in selected Igbo communities of Imo State, Nigeria. Afr J Reprod Health. 2002; 6(2):101-14.

14. Centers for Disease Control and Prevention (CDC). Costs of intimate partner violence against women in the United States. Atlanta: National Center for Injury Prevention and Control; 2003.

15. Coker AL, Davis KE, Arias I, Desai S, Sanderson M, Brandt HM, et al. Physical and mental health effects of intimate partner violence for men and women. Am J Prev Med. 2002;23(4):260-8.

16. Ludermir $A B$, Schraiber LB, D'Oliveira AF, França-Junior I, Jansen HA. Violence against women by their intimate partner and common mental disorders. Soc Sci Med. 2008; 66(4):1008-18.

17. Plichta SB. Intimate partner violence and physical health consequences: policy and practice implications. J Interpers Violence. 2004;19(11):1296-323.

18. Campbell JC. Health consequences of intimate partner violence. Lancet. 2002;359(9314): 1331-6.

19. Swanberg JE, Logan T, Macke C. Intimate partner violence, employment, and the workplace: consequences and future directions. Trauma Violence Abuse. 2005;6(4):286-312.

20. Browne A, Salomon A, Bassuk SS. The impact of recent partner violence on poor women's capacity to maintain work. Violence Against Women. 1999;5(4):393-426.

21. Martin J, Langley J, Millichamp J. Domestic violence as witnessed by New Zealand children. N Z Med J. 2006;119(1228):U1817.

22. Fergusson DM, Horwood LJ. Exposure to interparental violence in childhood and psychosocial adjustment in young adulthood. Child Abuse Negl. 1998;22(5):339-57.
23. Bangdiwala SI, de Paula CS, Ramiro LS Muñoz SR. Coordination of international multicenter studies: governance and administrative structure. Salud Publica Mex. 2003; 45(1):58-66.

24. Sistema Estadual de Análise de Dados/ Fundação SEADE. Informações dos municípios paulistas. Disponível em: www.seade. gov.br. Acessado em 10 de junho de 2007.

25. Bruschi A, de Paula CS, Bordin IA. Prevalência e procura de ajuda na violência conjugal física ao longo da vida [Lifetime prevalence and help seeking behavior in physical marital violence]. Rev Saude Publica. 2006;40(2): 256-64.

26. Associação Brasileira de Empresas de Pesquisa (ABEP). Critério de classificação econômica Brasil 2003. Disponível em: www.abep. org/novo/CMS/Utils/FileGenerate.ashx? id=21. Acessado em 11 de fevereiro de 2003.

27. Instituto Brasileiro de Geografia e Estatística. Censo Demográfico 2000. Nupcialidade e fecundidade. Disponível em: ibge.gov.br/ home/estatistica/populacao/censo2000/ nupcialidade_fecundidade/tabfecbr121.pdf. Acessado em 9 de março de 2010.

28. Hassan F, Sadowski LS, Bangdiwala SI, Vizcarra B, Ramiro L, De Paula CS, et al. Physical intimate partner violence in Chile, Egypt, India and the Philippines. Inj Control Saf Promot. 2004;11(2):111-6.

29. Araujo MF. Gênero e violência contra a mulher: o perigoso jogo de poder e dominação. Psicol Am Lat. 2008;14. Disponível em: psico latina.org/14/genero.html. Acessado em março de 2010 .

30. Reichenheim ME, Moraes CL, Szklo A, Hasselmann MH, Souza ER, Lozana JA, et al. The magnitude of intimate partner violence in Brazil: portraits from 15 capital cities and the Federal District. Cad Saude Publica. 2006; 22(2):425-37.

31. Rodgers K. Wife assault: the findings of a national survey. Juristat. 1994;14(9):1-21.

32. Briere J, Jordan CE. Violence against women: outcome complexity and implications for as- 
sessment and treatment. J Interpers Violence. 2004;19(11):1252-76.

33. International Clinical Epidemiology Network (INCLEN). WorldSAFE and IndiaSAFE: studying the prevalence of family violence. Filadélfia: INCLEN; 2000. (Inclen Monograph Series on Critical International Health Issues).

34. National Center for Injury Prevention and Control. Costs of intimate partner violence against women in the United States. Dispo- nível em: www.cdc.gov/violenceprevention/ pdf/IPVBook-a.pdf. Acessado em 9 de março de 2010.

35. Ellsberg MC, Winkvist A, Peña R, Stenlund H. Women's strategic responses to violence in Nicaragua. J Epidemiol Community Health. 2001;55(8):547-55.

36. International Center for Research on Women. Domestic violence in India: a summary report of a multi-site household survey. 2000. Dispo- nível em: icrw.org/docs/DomesticViolence3. pdf. Acessado em 9 de março de 2010.

Manuscrito recebido em 12 de setembro de 2009. Aceito em versão revisada em 5 de dezembro de 2009.

ABSTRACT Objectives. To estimate the lifetime prevalence of domestic violence against women (DVAW) in a low-income urban community and evaluate the immediate impact of DVAW on health, work, and family life.

\section{Life-long domestic violence against women: prevalence and immediate impact on health, work, and family}

Key words
Methods. The present cross-sectional study was carried out in the city of Embu (state of São Paulo, Brazil) as part of an international multicenter project (World Studies of Abuse in the Family Environment, WorldSAFE). A probabilistic sample of census sector-based clusters including all eligible households identified was used. A total of 784 women (age 16-49 years) with at least one child younger than 18 years and a lifetime resident husband/partner were included. We evaluated the occurrence of any kind of DVAW (slapping, kicking, hitting, beating, threatening to use or using a weapon, other aggressions mentioned spontaneously), of severe DVAW (same items, except slapping and other aggressions informed spontaneously), and of immediate impacts on the health, work, and family of the victims.

Results. The prevalence of DVAW was $26.0 \%$ for any kind of violence and $18.5 \%$ for severe DVAW. Among the victims of any kind of DVAW, 38.7\% judged that they needed medical care, $4.4 \%$ were hospitalized, $18.1 \%$ were incapacitated for work (paid work or household chores), 51.5\% left their partner due to the aggression and $66.7 \%$ had children who witnessed the violence. For severe violence, these rates were 51.0, $5.5,23.4,59.3$ and $75.9 \%$, respectively. Shame and fear of retaliation obstructed access to medical care.

Conclusions. The frequency of DVAW is high in the studied community and produces immediate impacts on the victim's health, work, and family life. These impacts decrease the victim's ability to look for help and hinder the breaking of the cycle of violence.

Domestic violence; violence against women; prevalence; impacts on health; psychosocial impact; Brazil. 